\title{
APP Spring Conference 1995
}

\section{Psychodynamic perspectives in old age psychiatry: a necessary integration}

This Conference, organised by the Association for Psychoanalytic Psychotherapy in the NHS, brought to the St Charles Day Hospital psychoanalysts and workers from different disciplines within NHS old age psychiatry services. Over 70 delegates attended, bringing varying experience of dynamic work.

Klaus Bergmann, an old age psychiatrist, entertainingly spoke of 'Neurosis in Older People, the Hunting of the Snark'. He described the difficulty of finding neurotic old people. Are old neurotics individuals who were always neurotic. now grown old? He thought not. Old age has its own problems. He quoted Bowlby and attachment theory as being involved in the aetiology of decompensation reactions to the threats of old age. Role expectation for elderly people is limited so that they are less likely to be recognised as being pathologically depressed, more likely to get tranquillisers and less likely to be referred to psychotherapy. Bergmann regretted his denial of a last chance to 'sort things out'. He cited Goldfarb who spoke of the need within the transference to balance the power disequilibrium that older people may feel with regard to their family and society.

Brian Martindale, a consultant psychotherapist, gave a thoughtful presentation 'From the Grave to the Cradle: Containment and the Elderly', agreeing with Erikson ('Ego Integrity v. Despair') that ageing is a developmental task but one in which timing and sequencing is unpredictable. In this last developmental cycle, despair is disintegration, unconsciously repeating the despair or failure of dependency of infancy. Elders may fear a state of dependency on another for physical and psychological needs, fear that the other will not be 'good enough', and that they will be hated and wished dead. This fear of dependency is a reflection of earlier needs not being met. Someone whose phase-specific dependency needs have previously been met will achieve 'integrity' in old age. He related a lack of fear elderly people show of death to the timelessness of the unconscious which does not see death as a possibility. He linked this with Pearl King's idea of the illusion of eternal life within a therapeutic setting. This needs to be remembered when discharging or transferring patients. The patient who knows he can come back, may not need to.

Following each speaker, groups were facilitated by an old age psychiatrist and a psychoanalyst. Dynamic perspectives were considered to be useful, not only with particular patients, but also in supervision and liaison. Understanding by staff of powerful feelings experienced when working with older patients may improve the quality of care and prevent unwitting anti-therapeutic behaviours.

The day had positive feedback. The next step is to get a network of psychoanalysts willing to supervise work with older people in NHS settings. This is a beginning. There needs to be more research, more teaching, more conferences and more in the journals about an integrated approach rather than maintaining the rigid split between psychiatric and psychoanalytic work and literature.

-Jane Garner, Consultant Psychiatrist, Department of Old Age Psychiatry, Chase Farm Hospital Enfield EN2 8J/; and Sandra Evans, Consultant Psychiatrist, Psychiatry of Old Age Unit, Hackney Hospital, London E9 6BE

*Correspondence 